九州大学学術情報リポジトリ

Kyushu University Institutional Repository

\title{
Effect of Temperature Fluctuation on Biofilm Formation with Bacterial Interaction between Salmonella enterica and Pseudomonas putida
}

Morimatsu, Kazuya

Research Fellow of the Japan Society for the Promotion of Science, Graduate School of Bioresource and Bioenvironmental Sciences, Kyushu University

Hamanaka, Daisuke

Laboratory of Postharvest Science, Faculty of Agriculture, Kyushu University

Tanaka, Fumihiko

Laboratory of Postharvest Science, Faculty of Agriculture, Kyushu University

Uchino, Toshitaka

Laboratory of Postharvest Science, Faculty of Agriculture, Kyushu University

https://doi.org/10.5109/26171

出版情報: 九州大学大学院農学研究院紀要. 58 (1)，pp.125-129，2013-02. Faculty of Agriculture， Kyushu University

バージョン :

権利関係 : 


\title{
Effect of Temperature Fluctuation on Biofilm Formation with Bacterial Interaction between Salmonella enterica and Pseudomonas putida
}

\author{
Kazuya MORIMATSU ${ }^{1}$, Daisuke HAMANAKA ${ }^{2}$, Fumihiko TANAKA ${ }^{2}$ \\ and Toshitaka UCHINO ${ }^{2 *}$
}

\author{
Laboratory of Postharvest Science, Department of Bioproduction Environmental Sciences, \\ Faculty of Agriculture, Kyushu University, Fukuoka 812-8581, Japan \\ (Received October 31, 2012 and accepted November 8, 2012)
}

\begin{abstract}
Many previous studies have focused on biofilm formation of microorganisms under steady state, however, in actual environment around food, surroundings of food frequently fluctuate. This study investigated the bacterial biofilm formation and interaction between different strains under constant and fluctuating temperature conditions.

Firstly, biofilm formation in mixed culture of Pseudomonas putida with Salmonella enterica under a constant temperature of $5^{\circ} \mathrm{C}$ and $30^{\circ} \mathrm{C}$ was investigated to identify the interactions between the two species. In the result, at $5^{\circ} \mathrm{C}, P$. putida principally formed biofilm in the mixed culture with $S$. enterica while $S$. enterica could neither form biofilm nor grow well. And, an interaction between $S$. enterica and P. putida could not be observed at $5^{\circ} \mathrm{C}$. In contrast, at $30^{\circ} \mathrm{C}$, the acceleration of biofilm formation was observed under only poor nutrient condition. It can be considered that the bacterial interaction induced by a lack of nutrient accelerated biofilm formation in the mixed culture.

Secondly, the effect of two different patterns of temperature fluctuation on biofilm formation in the mixed culture was studied by investigating the biofilm amount and bacterial count. In consequence, temperature fluctuation inhibited biofilm formation in the mixed culture of $S$. enterica with $P$. putida. However, salmonella count was promoted in comparison with that at the low constant temperature of $5^{\circ} \mathrm{C}$. In summary, the stress due to a lack of nutrient caused the bacterial interaction between $S$. enterica and $P$. put$i d a$ and accelerated biofilm formation in the mixed culture while fluctuating temperature had an inhibition effect on biofilm formation. However, considering the salmonella growth through temperature fluctuation, it is important to keep temperature constant during food distribution.
\end{abstract}

Key words: biofilm formation, fluctuating temperature, mixed culture, Pseudomonas putida, Salmonella enterica

\section{INTRODUCTION}

Bacteria attaching to food and food contact surfaces sometimes form biofilm. The attached cell produce extracellular polysaccharide for embedding the cell in a mature process of biofilm. Bacterial cell in these matured biofilm would come to have excessive tolerance against several stresses such as heat, chemical, etc. (Zottola et al., 1994). Hence, the contamination caused by biofilm-forming bacteria has been received much attention as serious problems related to food safety. Most of previous studies, which reported about biofilm formation, have focused on the single microbial species and have been conducted under steady environmental culture conditions. In fact, there are many kinds of microbial species in an actual situation and surroundings around the microorganisms frequently fluctuate. For example, a temperature fluctuation is observed during distribution of food and agricultural produce (Jacxsens et al., 2002, Uchino et al., 2006).

Research Fellow of the Japan Society for the Promotion of Science, Graduate School of Bioresource and Bioenvironmental Sciences, Kyushu University, 6-10-1, Hakozaki, Higashi-ku, Fukuoka, 812-8581, Japan, E-mail: km19851120@gmail.com

2 Laboratory of Postharvest Science, Faculty of Agriculture, Kyushu University, 6-10-1, Hakozaki, Higashi-ku, Fukuoka, 812-8581, Japan

* Corresponding author-Phone \& Fax: +81-92-642-2934, E-mail: toshiu@bpes.kyushu-u.ac.jp
However, there have been few studies conducted under an unsteady condition surrounding food. In response to this situation, Morimatsu et al. (2009, 2010) investigated the effect of temperature fluctuation on biofilm formation in a single culture of Pseudomonas putida and Salmonella enterica. Gram-negative bacteria, into which $P$. putida and $S$. enterica is classified, produce N-acyl-homoserine lactones as a signal material among different bacterial species, and a bacterial interaction through N-acyl-homoserine lactones enhance microbial biofilm formation (Kjelleberg et al., 2002). Moreover, any microbial biofilms are generally developed under multi-existent condition of various species of microorganisms, and the interaction in the microbial community may enhance the thickness and stability of biofilm, as James et al. (1995). Therefore, taking the actual food environment and the mutual action among different bacterial species into consideration, an effect of a bacterial interaction on biofilm formation under the unsteady condition should be investigated.

The present study aims to clarify the interaction between $S$. enterica and $P$. putida by examining biofilm formation in a mixed culture of these species under constant temperature, and to explain the effect of temperature fluctuation on the biofilm formation in the mixed culture. 


\section{MATERIALS AND METHODS}

\section{Bacterial strains and growth conditions}

The bacterial strains were Salmonella enterica. subsp. enterica NBRC 13245-derived strain from NITE Biological Resource Center (NBRC) and Pseudomonas putida, which was isolated from cucumber fruits and identified by analyzing base sequence of $16 \mathrm{~S}-\mathrm{rDNA}$ region using PCR method. S. enterica is one of the main food poisoning bacteria and $P$. putida is one of the genus Pseudomonas with a good ability to form biofilm. Both strains were cultured in Tryptic Soy Broth (TSB) at $25^{\circ} \mathrm{C}$ with agitation of 105 rpm for 3 days.

\section{Biofilm formation on an inner surface of polysty- rene tube in mixed culture}

Biofilm formation test on an inner surface of a polystyrene tube was prepared according to the method proposed by Planchon et al. (2006) with some modifications. Each salmonella and pseudomonal subcultures were diluted with sterile distilled water until optical density (OD) at $600 \mathrm{~nm}$ was adjusted to a value of 1.0. Salmonella culture was mixed with pseudomonal culture so that initial bacterial count of this mixed culture was $7.4 \times$ $10^{8} \mathrm{CFU} / \mathrm{ml}$. The mixed culture of $0.1 \mathrm{ml}$ was distributed in a prepared $15 \mathrm{ml}$ polystyrene tube with $5 \mathrm{ml}$ of TSB at $100 \%$ or $5 \%$ diluted with sterile distilled water, in order to identify the effect of nutrient concentration on biofilm formation. To attach bacteria onto the inner surface of the tube, the samples were allowed to stand for 30 minutes at room temperature. The tubes were then incubated in a incubator for 5 days at constant and fluctuating temperatures in order that the microorganisms form biofilms. The constant temperatures were set at $5^{\circ} \mathrm{C}$ and $30^{\circ} \mathrm{C}$, which reflected a refrigerated condition during the food distribution and a high-temperature in summer. In addition, two patterns of fluctuating temperature were applied. For the pattern (i) of fluctuating temperature condition, the tubes were incubated at ca. $5^{\circ} \mathrm{C}$ for 1 day, and after that these were incubated at ca. $30^{\circ} \mathrm{C}$ for 4 days. For the pattern (ii), the tubes were incubated at ca. $5^{\circ} \mathrm{C}$ for 1 day then at ca. $30^{\circ} \mathrm{C}$ for 1 day, after that the tubes were incubated at ca. $5^{\circ} \mathrm{C}$ for 3 days.

\section{Quantification assay for an amount of attached bio- film}

The quantification assay for an amount of attached biofilm was performed according to the method proposed by Stepanovic et al. (2000) with some modifications. After the incubation, solution in each tube was drained. Then, $5 \mathrm{ml}$ of sterile distilled water was distributed in each tube and drained to wash. Viable and dead cells with exopolysaccharides remaining onto the inner surface of the polystyrene tube after washing were defined as biofilm according to our previous study (Morimatsu et al., 2009). Subsequently, the attached cells and exopolysaccharides on the surface of each tube were stained with $5 \mathrm{ml}$ of $0.1 \%$ crystal violet solution for 10 minutes. After draining the solution, the inner surface was rinsed off by distributing and draining $5 \mathrm{ml}$ of sterile distilled water and then dried in a clean bench. The bound dye was resolubilized with $5 \mathrm{ml}$ of $99.5 \%$ ethanol for 1 minute by ultrasonication at $125 \mathrm{~W}-42 \mathrm{kHz}$ for one minute at room temperature. The OD of the solution obtained with the manner described above was measured at $500 \mathrm{~nm}$ to quantify the amount of biofilm by using the spectrophotometer according to the method described by Hamanaka et al. (2007). The quantification was performed in triplicate.

\section{Bacterial count in biofilm matrix of mixed culture}

To investigate the change in microbial flora of the biofilm, the viable bacterial number in the biofilm matrix was counted as follows. After the incubation, the solution in each tube was drained and washed once with $5 \mathrm{ml}$ of sterile distilled water and dried in the clean bench. Subsequently, $5 \mathrm{ml}$ of sterile distilled water was dispensed into each tube, and then the bacteria attached to the inner surface of the tube were resolubilized for 1 minute by ultrasonication at $125 \mathrm{~W}-42 \mathrm{kHz}$ for one minute at room temperature. After diluting the bacterial suspension, standard method agar for counting both $P$. putida and $S$. enterica, and X-SAL agar for $S$. enterica was mixed with the bacterial suspension in a petri dish. Each of the petri dishes were incubated at $25^{\circ} \mathrm{C}$ for 48 hours and $37^{\circ} \mathrm{C}$ for 24 hours, respectively. After the incubation, the colonies on the agar were counted for calculat-
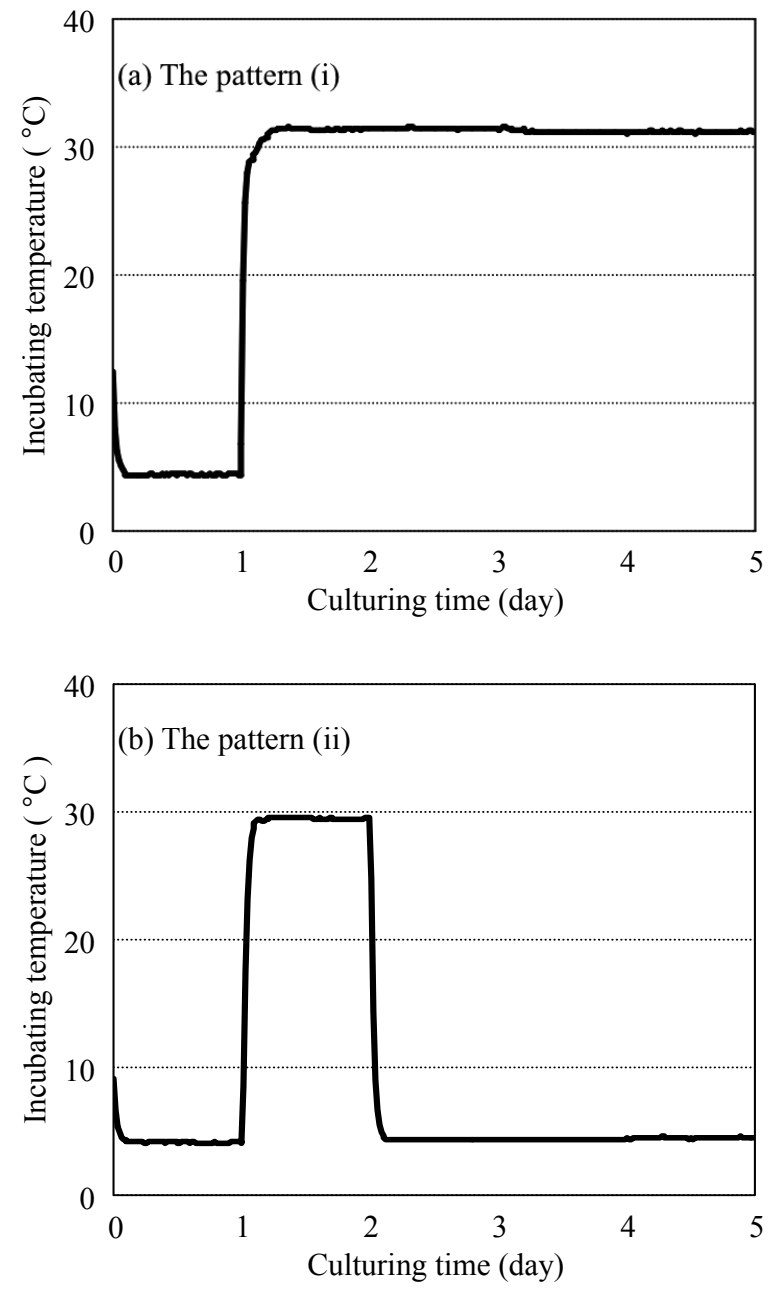

Fig. 1. Profile of fluctuating temperature condition. 
ing total bacterial count of P. putida and S. enterica, and salmonella count in the biofilm matrix. The experiment was performed at least three times.

\section{Statistical Analysis}

The mean value of OD and viable count for each day were statistically evaluated using the modified t-test based on Ryan's multiple test. $(P<0.05)$.

\section{RESULTS AND DISCUSSION}

At the low constant temperature of $5^{\circ} \mathrm{C}$, an amount of attached biofilm in the mixed culture of $P$. putida with $S$. enterica increased with cultivating time regardless of TSB concentration (Fig. 2). With cultivation time, total bacterial count increased while salmonella count decreased. Additionally, in our previous study (Morimatsu et al., 2010), P. putida actively formed biofilm at $5^{\circ} \mathrm{C}$ in the single culture while $S$. enterica kept a low level of biofilm amount from the beginning to the end of culture. Therefore, in the mixed culture at the low constant temperature of $5^{\circ} \mathrm{C}, P$. putida principally formed biofilm, while $S$. enterica could neither form biofilm nor grow well same as the single cultures. A bacterial interaction between $P$. putida and $S$. enterica could not be recog-
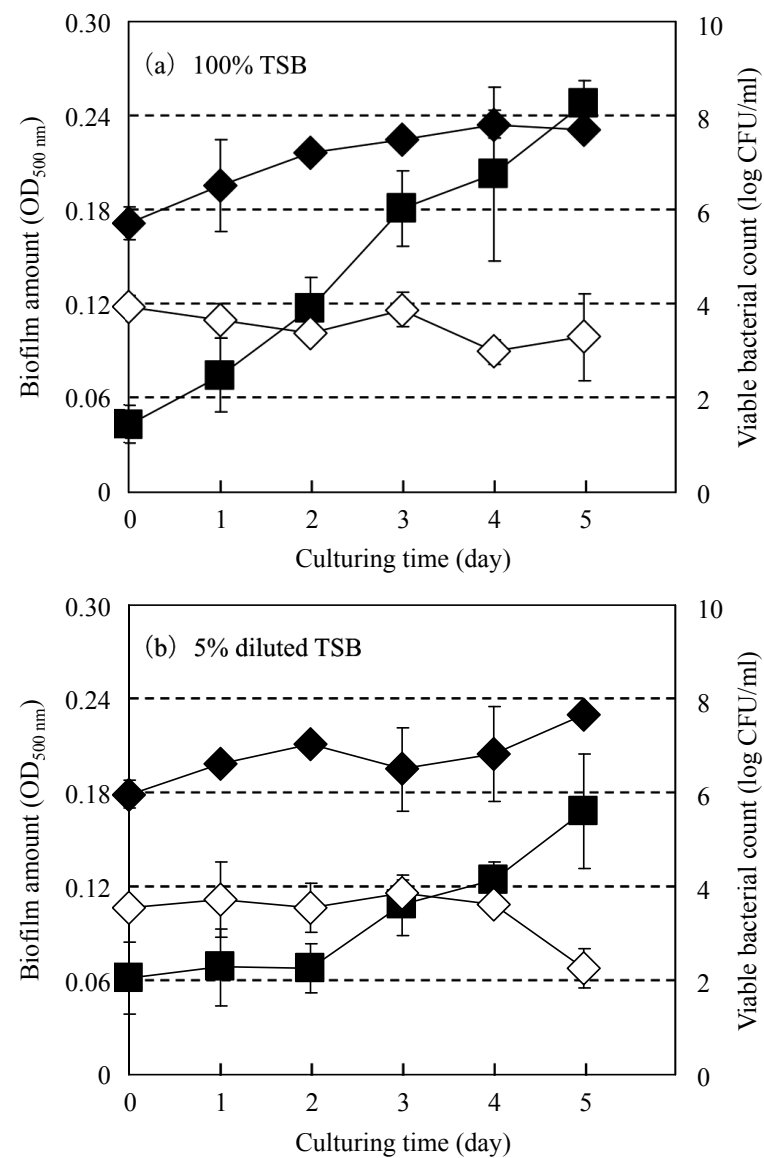

Fig. 2. Biofilm amount indicated by absorbance and viable bacterial count in biofilm matrix in the mixed culture of $P$. putida with $S$. enterica at $5^{\circ} \mathrm{C}$.

: biofilm amount in mixed culture of $P$. putida with $S$. enterica $\diamond$ : total bacterial count $\diamond$ : salmonella count nized in the mixed culture at $5^{\circ} \mathrm{C}$ because the biofilm amount in the mixed culture did not markedly increase in comparison with the single culture of $P$. putida in our previous study.

At the high constant temperature of $30^{\circ} \mathrm{C}$, the biofilm amount in the mixed culture with 100\% TSB decreased from 2 nd day to the 5 th day after a rapid increase on the 1st day, while the amount using 5\% diluted TSB increased until 3rd day and was kept over the culturing period (Fig. 3). From the result of our previous study (Morimatsu et al., 2010), S. enterica in the single culture with high nutrient broth formed biofilm similar to the result of the present research shown in Fig. 3 above however P. put$i d a$ could not form the biofilm actively, moreover both of microbial strains in the single culture with low nutrient broth formed less amount of biofilm comparing to that in high nutrient broth. Considering these facts, the biofilm formation could be accelerated only in the mixed culture using low TSB. Therefore, it appeared that a lack of nutrient at a high temperature, that is to say, unfavorable environment for microbe could enhance the bacterial interaction between $P$. putida and S. enterica, and biofilm formation could be accelerated by enhancement of the bacterial interaction.

Under the condition of fluctuating temperature of
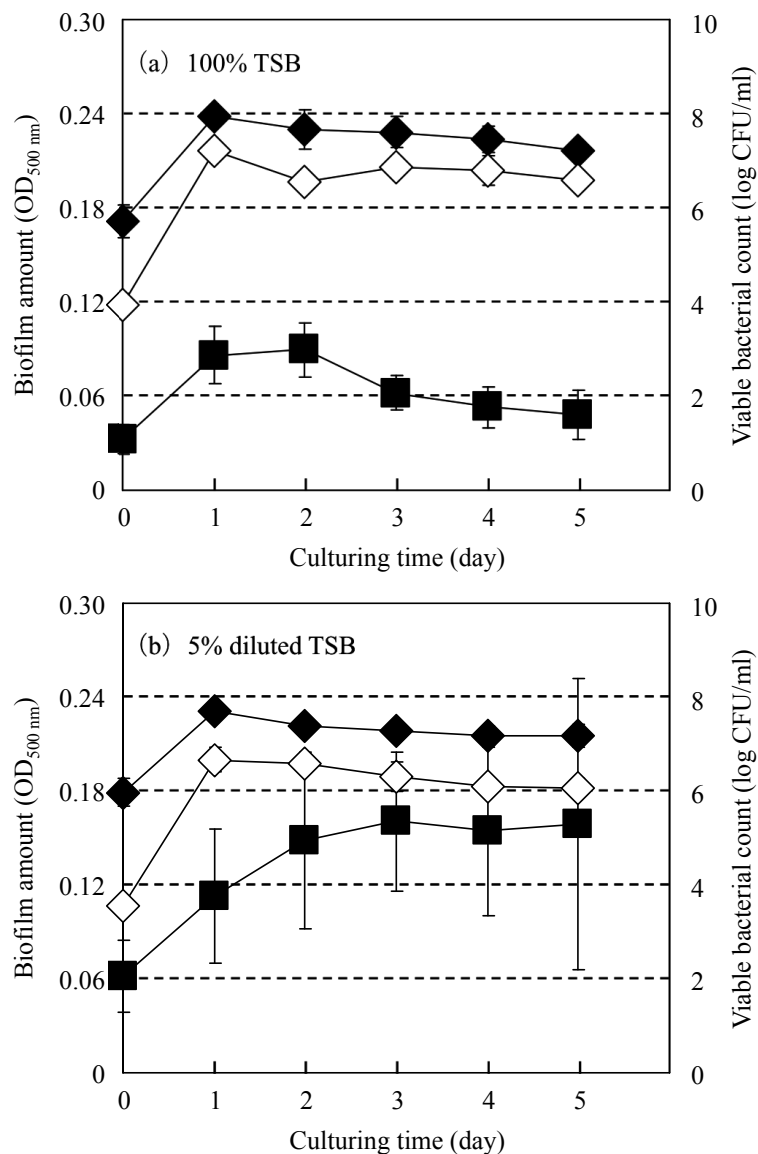

Fig. 3. Biofilm amount indicated by absorbance and viable bacterial count in biofilm matrix in the mixed culture of $P$. putid with $S$. enterica at $30^{\circ} \mathrm{C}$.

$\square$ : biofilm amount in mixed culture of $P$. putida with $S$. enterica $\diamond$ : total bacterial count $\diamond$ : salmonella count 
the pattern (i), the biofilm amount in 100\% TSB significantly decreased from the 2 nd day to the 5th day after a increase in the biofilm amount until the 2nd day, while the biofilm amount in 5\% diluted TSB significantly increased from the 1 st day to the $3 r$ day after a rise in temperature from $5^{\circ} \mathrm{C}$ to $30^{\circ} \mathrm{C}(P<0.05)$ (Fig. 4). At the high constant temperature, the bacterial interaction between $P$. put$i d a$ and $S$. enterica could accelerate biofilm formation in the poor nutrient in contrast to that in the rich nutrient (Fig. 3). Taking this result into consideration, biofilm formation in 5\% diluted TSB could be induced by the bacterial interaction between $P$. putida and $S$. enterica under the condition of the pattern (i). However, the biofilm amount was significantly less than that at the high constant temperature over the culturing day except for on the 4 th day and the 5 th day $(P<0.05)$. Therefore, temperature fluctuation at the pattern (i) could inhibit the biofilm formation accelerated by the bacterial interaction.

Under the condition of fluctuating temperature of the pattern (ii), although both of the biofilm amounts in $100 \%$ and $5 \%$ diluted TSB increased from the 2nd day to the 5th day after temperature declined (Fig. 5), this increase in the biofilm amount was less than that at the low constant temperature. Thus, an effect of temperature fluctuation of the pattern (ii) could inhibit the biofilm
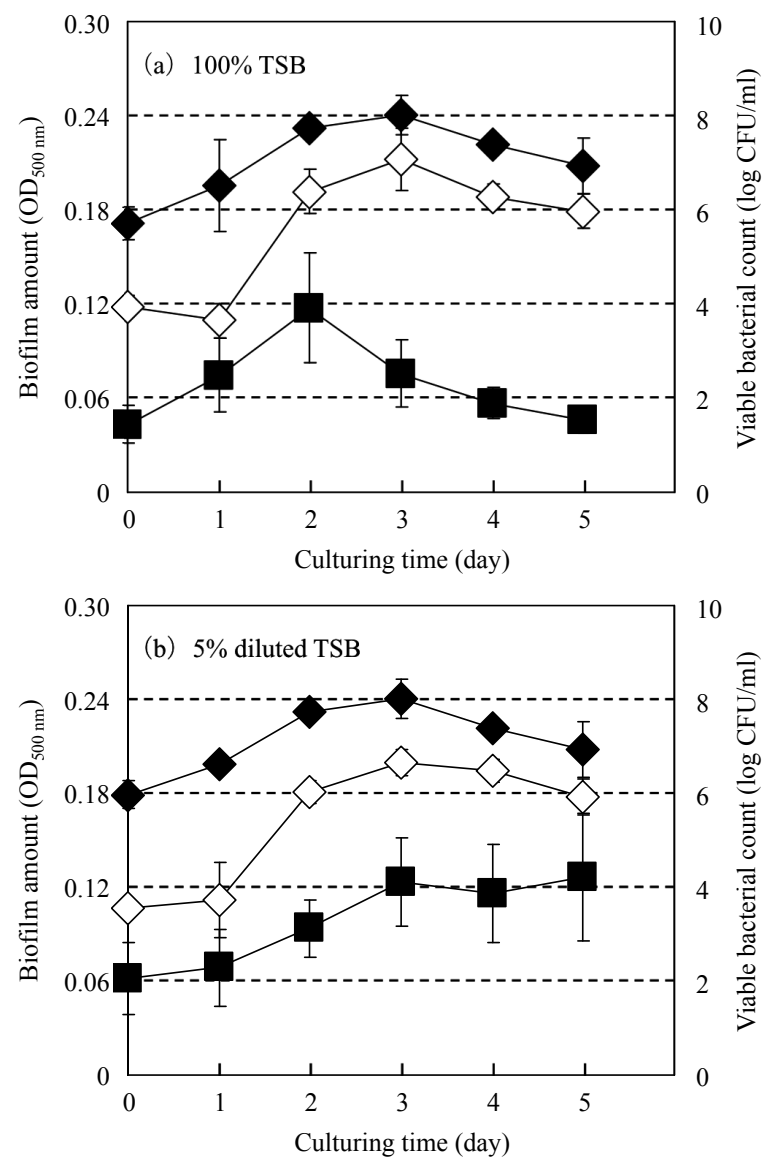

Fig. 4. Biofilm amount indicated by absorbance and viable bacterial count in biofilm matrix in the mixed culture of $P$. putida with $S$. enterica at the pattern (i) of fluctuating temperature condition.

: biofilm amount in mixed culture of $P$. putida with S. enterica $\diamond$ : total bacterial count $\diamond$ : salmonella count formation. However, temperature fluctuation of the pattern (ii) could help the survival of $S$. enterica at a low temperature of $5^{\circ} \mathrm{C}$ after the 3rd day because the salmonella count was significantly high in comparison with that at the low constant temperature conditions in all culturing days $(P<0.05)$.

Overall, the result of this study on biofilm formation by the bacterial interaction between $P$. putida and $S$. enterica can be summarized as follows: (a) At low constant temperature, $P$. putida became the dominant species in terms of biofilm formation; the bacterial interaction related with biofilm formation was not observed. (b) At high temperature, a stress of poor nutrient condition induced the bacterial interaction. As a result, biofilm formation in the mixed culture of $P$. putida with $S$. enterica was accelerated. (c) Inhibition of biofilm formation by temperature fluctuation was observed, however, temperature fluctuation of the pattern (ii) helped the survival of $S$. enterica at low temperature. Taking a growth of $S$. enterica through temperature fluctuation into consideration, it was indicated that an unsuitable temperature fluctuations in food distribution may pose a high risk of food poisoning. Thus, it is important to maintain a constant temperature during food distribution.
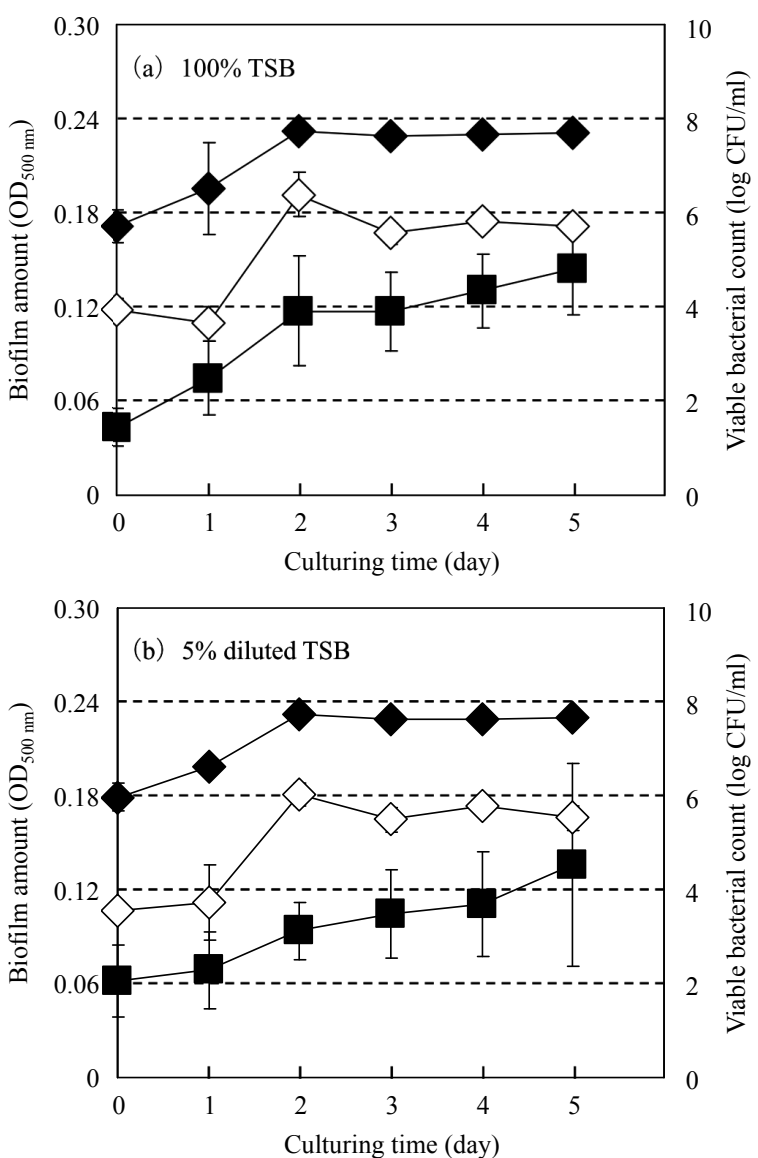

Fig. 5. Biofilm amount indicated by absorbance and viable bacterial count in biofilm matrix in the mixed culture of $P$. putida with $S$. enterica at the pattern (ii) of fluctuating temperature condition.

口: biofilm amount in mixed culture of $P$. putida with $S$. enterica $\diamond$ : total bacterial count $\diamond$ : salmonella count 


\section{REFERENCES}

Hamanaka, D., Niihara, A., Umezaki, H., Atungulu, G. G., Tanaka, F., Uchino, T. 2007 Effect of culture condition on the adhesion of bacteria isolated from cucumber fruit. Proc. of Int. Semin. on Agric. Struct. and Agric. Eng., 746: 130-135

Jacxsens, L., Devlieghere, F., Debevere, J. 2002 Predictive modeling for packaging design: equilibrium modified atomosphere packages of fresh-cut vegetables subjected to a simulated distribution chain. Int. J. Food Microbiol., 73: 331-341

James, G. A., Beaudette, L., Costerton, J. W. 1995 Interspecies bacterial interactions in biofilms. J. Ind. Microbiol., 15: 257262

Kjelleberg, S., and Molin, S. 2002 Is there a role for quorum sensing signals in bacterial biofilms?. Curr. Opin. Microbio., 5: $254-258$

Morimatsu, K., Hamanaka, D., Uchino, T., Tanaka, F. 2009 Effect of fluctuating temperatures on the surface adherence of Salmonella enterica and Staphylococcus aureus. J. Antibact.
Antifungal Agents, 37: 565-571

Morimatsu, K., Hamanaka, D., Uchino, T., Tanaka, F. 2010 Effect of mixed culture of two bacteria on biofilm formation under fluctuating temperature. 5th Int. Symp. Machin. Mechatro. for Agric. Biosys. Eng., P. 57

Planchon, S., Gaillard-Martinie, B., Dordet-Frisoni, E., BellonFontaine, M. N., Leroy, S., Labadie, J., Hébraud, M., Talon., R. 2006 Formation of biofilm by Staphylococcus xylosus. Int. J. Food Microbiol., 109: 88-96

Stepanovic, S., Vukovic, D., Dakic, I., Savic, B. 2000 A modified microtiter-plate test for quantification of staphylococcal biofilm formation. J. Microbiol. Methods, 40: 175-179

Uchino, T., Nei, D., Sakai, N. 2006 Temperatures of fresh vegetables and in the refrigerated truck body during transportation. J. JSAM, 68: 72-77

Zottola, E. A., Sasahara, K. C. 1994 Microbial biofilms in the food processing industry - Should they be concern? Int. J. Food Microbiol., 23: 125-148 